\title{
MECANISMOS URBANÍSTICOS Y GESTIÓN PÚBLICA EN EL EJERCICIO DEL DERECHO CONSTITUCIONAL A UNA VIVIENDA DIGNA.
}

\author{
Enrique de la Villa Polo (Arquitecto - Profesor asociado DUyOT)
}

Pese a la inexistencia de un desarrollo normativo específico del artículo 47 de la Constitución Española en el que se establece el derecho de todos los ciudadanos a una vivienda digna y adecuada, el fracaso en la ejecución efectiva de este derecho en los treinta y siete años transcurridos desde su aprobación, no es achacable a un erróneo diseño de los mecanismos legales para ello, sino a un deficiente manejo de estos mecanismos por los poderes públicos responsables de su aplicación.

El derecho de todo ciudadano disfrutar de una vivienda contenido en la el artículo 25 de la Declaración Universal de los Derechos Humanos, fue recogido en la Constitución Española de 1978, en su artículo 47. En él se establece que corresponde a los poderes públicos promover las condiciones necesarias y aprobar las normas pertinentes para hacerlo efectivo. A diferencia de otros derechos constitucionales, éste requiere de un desarrollo normativo para su aplicación.

Sin una norma legal que desarrolle el concepto constitucional de "vivienda digna y adecuada", la Oficina del Alto Comisionado de las Naciones Unidas para los Derechos Humanos en su Observación General no 4, considera que es aquella "donde los ciudadanos o las familias pueden vivir con seguridad, paz y dignidad". Parece claro que en esta definición la satisfacción del derecho a una vivienda va más allá de resolver el cobijo. Se trata de cubrir además otras necesidades. Como consecuencia, la regulación del derecho a la vivienda para el cumplimiento del mandato constitucional, además de abordarse desde su componente económica y edificatoria, es un aspecto que compete a la regulación sobre suelo y urbanismo, en la medida que afecta a otros aspectos de la vida colectiva.

Aproximándonos más al concepto, la Resolución 2012/2293(INI) del Parlamento Europeo, de 11 de junio de 2013, sobre la vivienda social en la Unión Europea identifica el derecho a una vivienda adecuada, como "la necesidad de promover el acceso de las personas con menos recursos a una vivienda segura y bien ubicada". Por tanto la regulación de este derecho, que por mandato constitucional deben garantizar los poderes públicos, debe incidir sobre a tres factores: Capacidad económica de los ciudadanos, seguridad de la edificación, y planificación de la estructura urbana.

Respecto a la seguridad, vinculada a las condiciones físicas de la edificación, la garantía queda cumplida con la aplicación de estándares mínimos de calidad idénticos en toda construcción independientemente de su destino. Algo que en el ordenamiento español regula el Código Técnico de la Edificación de 2007.

Respecto a la capacidad económica de los ciudadanos como factor de garantía de acceso a la vivienda, en un sistema inmobiliario regido exclusivamente por las reglas del libre mercado, el ejercicio de este derecho estaría directamente vinculado con la renta disponible de los ciudadanos. Las únicas medidas para garantizar este derecho, 
serán aquellas dirigidas a aumentar esta renta. No siendo así, corresponde a los poderes públicos intervenir en el sistema inmobiliario. Esta es la vía apuntada por la constitución española, cuando, el mismo artículo 47 en el que se establece el derecho a una vivienda digna, contiene el mandato de regular la utilización del suelo de acuerdo con el interés general, impedir la especulación, y la participación de la comunidad en las plusvalías que genere la acción urbanística de los entes públicos.

La actividad urbanística en España, tiene entre sus principios rectores el control de la especulación, y la reversión de las plusvalías. Los instrumentos de planeamiento en los que se recogen los modelos territoriales y locales de ordenación, tienen, entre otras, la función de propiciar la producción de viviendas de precio regulado que den cobertura a población con niveles de renta insuficientes para acceder al mercado libre, y destinar recursos para la creación de un parque inmobiliario público. Corresponde además a los Planes urbanísticos fijar las estrategias municipales para la ubicación concreta de estas viviendas, y la programación para su desarrollo.

Partiendo de la definición de la Resolución del Parlamento Europeo sobre la vivienda social en la Unión Europea, corresponden a la actividad urbanística dos de los tres aspectos sobre los que deben actuar los poderes públicos para facilitar el acceso a la vivienda: la previsión y programación de las viviendas dirigidas a población con niveles de renta más bajo, y la planificación de la estructura urbana. Por tanto, el camino hacia un ejercicio real del derecho constitucional a una vivienda digna y adecuada, pasa necesariamente por el planeamiento urbanístico.

De ello derivan algunos factores capitales que han condicionado la satisfacción del derecho a la vivienda. La distribución de competencias entre las administraciones del estado, comunidades y municipios, reparte la responsabilidad respecto al diseño de mecanismos legales e instrumentos estratégicos y tácticos que los desarrollen, y la implementación de los mismos. En este contexto, la ejecución de los instrumentos de ordenación municipal, los Planes General de Ordenación o equivalentes, es una competencia casi exclusivamente municipal. Como lo es la utilización de las plusvalías generadas por la actividad urbanística para la constitución de un Patrimonio Municipal de Suelo. Y es en esta escala de intervención en la que todo el proceso se ha mostrado más débil.

El concepto de Patrimonio Municipal de Suelo se incorporó a la legislación española en el Reglamento de Bienes de las Corporaciones Locales de 1955, como obligación de destinar un $5 \%$ del presupuesto del Ayuntamiento para su adquisición, pasando desde la Ley del Suelo de 1976 a generarse por cesión obligatoria de un porcentaje del aprovechamiento urbanístico. También la definición de su destino fue matizándose con el tiempo, y desde una finalidad genérica, pasó a vincularse con la intervención municipal en el mercado inmobiliario, de acuerdo con el interés general. Esta vinculación se produjo con la aprobación del TRLS de 1992, que preveía también la sustitución de la cesión de suelo por su equivalente económico, con obligación de destinarlo a la conservación y ampliación de este patrimonio.

La Sentencia del Tribunal Constitucional de 20 de marzo de 1997, reconoció la competencia del estado para la definición y destino del Patrimonio Municipal del Suelo, como patrimonio separado del resto de los bienes municipales. De este modo, el RDL 2/2008 por el que se aprueba la vigente Ley del Suelo del Estado, establece como destino de este suelo regular el mercado inmobiliario, bien mediante la construcción 
de viviendas sujetas a algún régimen de protección pública, bien enajenando terrenos a un precio no especulativo. En todo caso, los ingresos obtenidos mediante enajenación de terrenos o sustitución del aprovechamiento correspondiente a la Administración por su equivalente metálico deben necesariamente destinarse a la conservación y ampliación del Patrimonio Municipal de Suelo, y en ningún caso a la financiación de otras partidas de los presupuestos municipales. Una exigencia legal que sistemáticamente se ha incumplido en los municipios españoles.

Por tanto los mecanismos legales para permitir el derecho de todos a una vivienda digna, y los instrumentos para hacerlo efectivo, existen aún antes del mandato constitucional para ello. Y sin embargo, según datos de la oficina del Defensor del Pueblo, en 2013 había en torno a 276.000 viviendas públicas en España, 250.000 de las cuales están gestionadas por las comunidades autónomas y 26.000 por grandes municipios. El último censo oficial de población y vivienda de 2011 indica que España tiene 25,2 millones de viviendas. Por tanto, la vivienda social sería aproximadamente el $1,1 \%$ del sector de la vivienda en su conjunto. Este porcentaje es Ilamativamente bajo si se compara con países que han resuelto de forma razonablemente efectiva el ejercicio del derecho a la vivienda. En particular en Holanda el porcentaje alcanza el $32 \%$, y es del $23 \%$ en Austria, del $18 \%$ de Reino Unido y del $17 \%$ de Francia. De hecho, dentro del grupo de los 15 de la Unión Europea, sólo Grecia presenta un dato inferior a España.

A pesar de esta situación, el gasto público en vivienda desde el comienzo de la crisis económica en 2007 ha disminuido. La partida de vivienda de los Presupuestos Generales del Estado se redujo en más de la mitad entre 2008 y 2015 . Las ayudas a la vivienda descendieron de 40,95 euros por persona en 2008 a 27,79 en 2012, frente a los 134,65 euros de promedio de la Unión Europea en el 2012.

Incluso en este contexto, la Resolución 2012/2293(INI) del Parlamento Europeo, de 11 de junio de 2013, sobre la vivienda social en la Unión Europea, para la materialización del derecho a la vivienda proponía medidas que fácilmente podrían ponerse en práctica aun habiendo fallado las políticas públicas de suelo. Medidas tales como realizar auditorías de las viviendas y los edificios desocupados para definir estrategias al respecto, combatir la especulación y la infrautilización de las viviendas privadas, y regular las instituciones financieras y el mercado de financiación en relación con la vivienda, entre otras.

El número de viviendas vacías en España era de tres millones cuatrocientas cuarenta mil en 2011, según el último censo, lo que constituye un importante recurso potencialmente disponible que las autoridades públicas podían usar para garantizar el derecho a la vivienda. Sin embargo las autoridades públicas, salvo excepciones, desatendiendo las medidas propuestas por el Parlamento Europeo, no lo han puesto en valor. En algunos casos como en Cataluña y la Comunidad de Madrid incluso se ha retrocedido al respecto, disminuyendo los plazos para que una vivienda pública pueda pasar a manos privadas, o vendiendo las disponibles a sociedades de inversión, reduciendo así un parque ya limitado.

Por todo lo expuesto, existen los mecanismos legales para hacer efectivo el derecho de todos los ciudadanos a una vivienda digna y adecuada, si bien para ello las administraciones deben necesariamente ordenar su territorio incorporando esta necesidad, dando prioridad a la función social del suelo y las viviendas sobre los 
derechos de propiedad. Y este es un paso que a la vista de las cifras, las políticas municipales han dado insuficientemente. Analizar las razones para ello escapa del ámbito del urbanismo.

\section{REFERENCIAS BIBLIOGRÁFICAS:}

CIRIA PEREZ, F.J.: "Destino del Patrimonio Publico o Municipal del suelo" en Revista de Administración Local no 17. (1998).

MARTÍN HERNÁNDEZ, P.: "El Patrimonio Municipal del Suelo: Su evolución normativa. (2006).

AMNISTÍA INTERNACIONAL. Informe. "El derecho a la Vivienda y los desalojos hipotecarios en España" (2015) 